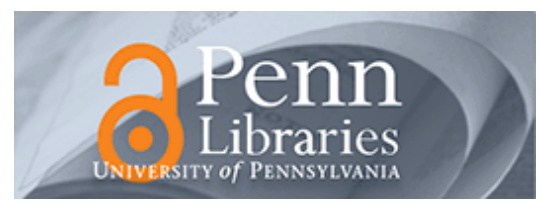

University of Pennsylvania

ScholarlyCommons

Finance Papers

Wharton Faculty Research

6-2017

\title{
Pricing Theater Seats: The Value of Price Commitment and Monotone Discounting
}

Necati Tereyagoglu

Peter S. Fader

University of Pennsylvania

Senthil K. Veeraraghavan

University of Pennsylvania

Follow this and additional works at: https://repository.upenn.edu/fnce_papers

Part of the Business Administration, Management, and Operations Commons, and the Finance and Financial Management Commons

\section{Recommended Citation}

Tereyagoglu, N., Fader, P. S., \& Veeraraghavan, S. K. (2017). Pricing Theater Seats: The Value of Price Commitment and Monotone Discounting. Production and Operations Management, 26 (6), 1056-1075. http://dx.doi.org/10.1111/poms.12611

This paper is posted at ScholarlyCommons. https://repository.upenn.edu/fnce_papers/69

For more information, please contact repository@pobox.upenn.edu. 


\title{
Pricing Theater Seats: The Value of Price Commitment and Monotone Discounting
}

\author{
Abstract \\ We examine the value of price commitment in a non-profit organization using individual-level purchases \\ over a series of concert performances. To decide on a pricing policy, the performing arts organization \\ must be able to accurately measure when each ticket will be sold and what type of audience will purchase \\ the tickets for each performance. We use a competing hazards framework to model the timing of ticket \\ purchases when customer segments differ in their valuations and arrival times. We show that the \\ customer purchase likelihoods change based on the prices observed earlier in the season. Hence, price \\ commitment can aid in improving sales, revenues, and customer visits. In particular, we show that price \\ commitment to a decreasing monotone discount policy can improve the revenues in the range $2.1 \%-6.7 \%$ \\ per concert.

\section{Disciplines} \\ Business | Business Administration, Management, and Operations | Finance and Financial Management
}




\title{
Pricing Theater Seats: The Value of Price Commitment and Monotone Discounting
}

\author{
Necati Tereyağoğlu \\ The Scheller College of Business, Georgia Institute of Technology, Atlanta, Georgia 30308, \\ necati.tereyagoglu@scheller.gatech.edu \\ Peter S. Fader, Senthil Veeraraghavan \\ The Wharton School, University of Pennsylvania, Philadelphia, PA 19104, \\ faderp@wharton.upenn.edu, senthilv@wharton.upenn.edu
}

\begin{abstract}
We examine the value of price commitment for a nonprofit organization using individual level purchases over a series of concert performances. To decide on a pricing policy, the performing arts organization must be able to accurately measure when each ticket will be sold and what type of audience will purchase the tickets for each performance. We use a competing hazards framework to model the timing of ticket purchases when customers differ in their valuations and arrival times. We show that the customer purchase likelihoods change based on the prices observed earlier in the season, and demonstrate how price commitment aid in improving sales and revenues. We provide insights into the revenue-generating capability of commitment to a pricing policy that can address the differences among customer segments. In particular, we show that price commitment to a monotone discount policy can improve the average revenues as high as $6.72 \%$ per concert.

Keywords: Non-Profit, Performing Arts Industry, Price Commitment, Survival Analysis, Competing Risks, Proportional Hazard.
\end{abstract}




\section{Introduction}

The media often reports crises in the symphony orchestra industry. The Philadelphia Orchestra filed for Chapter 11 bankruptcy in April 2011, the Honolulu Symphony and the Syracuse Symphony Orchestra ceased operations in 2011 as a result of financial problems (Schweitzer 2011), and the Atlanta Symphony Orchestra had to cancel its shows in the first few months of the 2014-15 season. Such observations are common.

With a decline in donations from private sponsors and large corporations, these nonprofit organizations are under increased pressure to generate more revenues from their ticket sales, to make it possible for their less lucrative but traditionally important performances to be shown. It may be profitable to include popular performers in the concerts, which would attract media attention for the orchestra and increase subscription ticket sales. However, subscription sales are reportedly lacking because of a changing social landscape with members of the "keep-your-options-open" generation that rarely commits to events months in advance (Schweitzer 2011). As a result, the orchestras are being forced to consider their revenuegenerating audiences across both subscribers and occasional buyers. Since all patrons are potential future donors, the organizations face the challenge of filling seats in the theaters (full houses) by careful discounting which improves customer goodwill, while generating healthy revenues to cover expenditures and fixed operating costs.

To meet such revenue objectives, managers in non-profit institutions are faced with the problem of accurately predicting when a seat in a particular seating section will be purchased, which customer category will purchase that seat, and how the organization's commitment to a particular pricing policy will influence those customer purchases. Our empirical model focuses on how the likelihood of purchase from each customer category changes over time based on the organization's pricing decisions and on other time-related factors. Managers then have the option to customize a pricing policy for a particular customer category and commit to this policy throughout the season.

Selling a good to customers with different valuations over time has led to the growth of 
theory of revenue-maximizing dynamic pricing policies. Both in practice and research, there has been a debate on various dynamic pricing models given the increasing evidence of various consumer purchase behaviors. Bitran and Mondschein (1997) argue that those dynamic policies may be hard to implement because of "non-trivial coordination and management costs" and customer aversion to seemingly "random" price oscillations. Such customer aversion has been noted in practice: Uber received harsh criticism from its own customers for its reliance on surge pricing policies (Surowiecki 2014). Similarly, customers, who buy ski lift tickets at high prices earlier in the season, reportedly feel unjustly treated when they see ski resorts dropping lift prices at the last minute (Deprez 2015). In the context of non-profits, such negative customer reactions are antithetical to both the endowment directives, and the organization's goal of progressing patrons to become donors.

Hence, commitment to pre-announced prices may allay some of the revenue losses related to forward-looking customer behavior, and may reduce consumer regret. For instance, Bitran and Mondschein (1997) suggest that commitment to a monotone increasing price policy will dissuade customers from waiting for discounts, and may provide revenue as good as an optimal discounting policy. In addition, such price commitments are easier to manage or coordinate between several agents. While commitment to a monotone price policy is appealing due to its simplicity in implementation, it also suffers from a delayed ability to respond to market changes. It is tempting to offer deep discounts - indeed, may provide higher sales - when there is a significant amount of left-over inventory. Hence, the efficacy of such price commitment policies is unclear: this is one principal focus of our study.

In fact, in the airline industry, the evidence for price commitment is mixed. While dynamic pricing is typically prevalent in most airline markets, there are also airlines that use some form of price commitment. Some airlines such as Southwest Airlines (Heskett and Sasser Jr 2010) follow a posted pricing model, in which prices of many seat segments are preannounced and are typically sold out in increasing prices; airlines such as easyJet (Koenigsberg et al. 2008) adopt a monotone increasing price policy. 
Very little is known on theoretical and empirical validation of such price commitment policies. For example, Li et al. (2014) examine strategic consumer behavior in depth in the airline market and mention that "non-decreasing price commitment to eliminate strategic behavior is not always preferable," particularly in leisure markets rife with strategic consumer behavior.

Given the state of mixed findings in industry, and the continuing theoretical debate concerning customer purchase behavior, our goal is to explore the value of price commitments when a non-profit performing arts organization sells a limited amount of inventory (theater seats) over a finite time horizon, using a customer level data set from a symphony orchestra. We are not aware of any other empirical research study on price commitments and in a performing arts setting.

Our key objective is to identify ways we can effectively use the information, such as the ticket purchase times and the category of customers making these purchases. This information may reveal the change in the likelihood of a ticket sale due to the organization's actions as the concert date approaches. We then use the result to test the effectiveness of price commitment; specifically, we explore the decreasing monotone discounting (DMD) policy for this organization.

To achieve this goal, we model the propensity of a ticket being sold at a particular point in time, as well as its dependencies on the organization's discounting actions and other timerelated factors. We focus on the two main customer categories in this setting: subscribers and occasional buyers. In each category, people may have different propensities to purchase a ticket.

We use the competing risks framework with proportional hazards to model the differences in purchase timings for the two customer types. The estimation of this framework documents how the propensity to sell a ticket to a particular customer segment changes over time in response to the discounts offered. We use this estimated framework to perform pricing experiments to assess the impact of commitment to a monotone decreasing discounting policy 
on the orchestra's revenues. The results show that commitment to a decreasing monotone discounting policy can increase the average revenue per concert by $6.72 \%$ relative to the current pricing policy of the organization.

\section{$2 \quad$ Related Literature}

Our research documenting the value of commitment to a monotone non-decreasing price policy draws from the literature on pricing in economics and marketing, as well as on revenue management in operations management.

Our empirical modeling of timing of ticket purchases considers potential interest for a ticket from two broad and distinct customer categories, in line with that of Dana (1998) and Koenigsberg et al. (2008), with each customer category exhibiting differing sensitivities to the organization's discount policies. In addition, the likelihood of a ticket purchase varies both by category and time.

Unlike prior research, we employ the hazard rate of each individual seat's sale to track how the likelihood of a sale to different customer categories changes over time in response to the organization's past and current pricing decisions. More specifically, instead of calibrating just the aggregate demand, we track individual seat's purchase likelihood and the likelihood of this seat being sold to a particular customer category in response to the organization's pricing decisions. Our hazard-based model can also be derived using a utility model. We then exploit the theoretical relationship between hazard rates and survival probabilities to link the likelihood of a seat's purchase with the pricing decisions of the organization.

Our hazard-based model corresponds to the extensive literature on longitudinal survival analysis in statistics. Traditionally, the model is used to analyze the time to the occurrence of an event, such as the death for a person with a particular disease or a failure in a mechanical system (Kleinbaum and Klein 2012). This framework can be extended to document the impact of a continuous implementation of a factor (such as a drug) on the time to the 
occurrence of a death using an exponential of a parametric linear functional form defined as proportional hazards (Cox 1972). Such models are appropriate for duration analysis in a variety of field settings - in music purchases (Moe and Fader 2002), customer retention (Fader and Hardie 2007), service acquisition (Schweidel et al. 2008a, 2008b), flight departure times (Deshpande and Arikan 2012), and production times (Terwiesch et al. 2005). We use this framework to model the time to the occurrence of a seat purchase and use the proportional hazards to examine the impact of the organization's discounts and some time-related factors on timing of that purchase. To the best of our knowledge, the employment of a duration model to match customer demand in a revenue management setting is new.

Our empirical analysis on documenting the value of commitment to a pricing policy draws from a rich body of research in dynamic pricing in revenue management, including Gallego and van Ryzin (1994, 1997) and Feng and Gallego (1995, 2000). We refer the reader to Talluri and van Ryzin (2004) for an extensive analysis of theory and practical issues in revenue management settings. The uncertainty in an organization's pricing action in subsequent periods may involve behavioral anomalies in the timing of purchases. Some consumers may delay their purchases in anticipation of a potential price drop. This behavior exists in the airline industry (Li et al. 2014). Recent papers that consider strategic customers show that organizations might have to follow a mark-up policy if high valuation customers are highly patient (Su 2007) or a fixed pricing policy (Ovchinnikov and Milner 2011).

Some researchers explore pricing decisions when the organization does not commit to a pricing policy. Koenigsberg et al. (2008) argue that an organization will benefit from a last-minute sale as long as there is uncertainty with respect to the organization's pricing decisions. However, a last-minute sale may lead to more consumers anticipating the discount and delaying their purchases, hence potentially reducing the revenue of the organization (Jerath et al. 2010).

A renewed theoretical interest in price commitments has shown such price commitments may be beneficial when customers exhibit varying degrees of patience (Liu and Cooper 2014, 
Besbes and Lobel 2015, and Caldentey et al. 2014).

We use the flexible competing hazards model, to run pricing analytics on the data, and show the revenue-generation capability of commitment to a non-increasing monotone discounting policy when customer classes have different valuations and arrival rates. Next, we describe how we implement the competing risks with proportional hazards framework in this setting.

\section{Model Description}

\subsection{Modeling Ticket Sales with Proportional Hazards}

The orchestra (organization) sells tickets for shows at a venue with capacity of $K$ seats divided into $j=1, \ldots, J$ zones for $N$ shows or performances in a season. The tickets are sold at some base price for each zone (or at a discounted price, if discounts prevail). Several types of discounts are offered. There are discounts for customers who buy tickets for a single show occasionally (occasional buyers), and those customers who buy tickets for multiple shows, or who subscribe to bundles (subscribers). Furthermore, if a subscriber buys tickets for multiple shows, he is allowed to inform the theater of the selections for the specific shows he desires to attend at any point in time before the show dates. Hence, in the data, the actual timing of the purchase of tickets for a particular show is when the selection bundles are chosen. We model the purchase timing of occasional buyers similarly.

We define the customer arrivals in the context of the timing of a ticket purchase by taking a seat perspective. Let $T \in(0, \infty)$ be the time to sell a ticket for a particular concert. Let $f(t)$ be the probability density function of selling a ticket for a seat at time $t$ and $F(t)=P(T<t)$ be the cumulative distribution function of selling a ticket until time $t$. Then, the survival function, the probability of a seat remaining empty until time $t$ would be $S(t)=1-F(t)$. The survival probability specifies the unconditional probability that the sale of a ticket for a seat has not happened by time $t$. The hazard rate $\lambda(t)$, on the other 
hand, is defined by means of a conditional probability. We look at those tickets that have not been sold by time $t$ and consider the probability of there being a ticket sale in the small time interval $[t, t+d t]$. Then, this probability would be equivalent to $\lambda(t) d t$. Mathematically, the hazard rate is defined as a limit in the following way,

$$
\lambda(t)=\lim _{h \rightarrow 0} \frac{\operatorname{Pr}(t \leq T<t+h \mid T \geq t)}{h}=\lim _{h \rightarrow 0} \frac{1}{h} \frac{S(t)-S(t+h)}{S(t)} .
$$

In that case, the instantaneous hazard rate of selling a ticket would be $\lambda(t)=-\frac{S^{\prime}(t)}{S(t)}$ if $T$ is absolutely continuous.

We can write the survival rate of the seat at time $t$ using the boundary condition $S(0)=1$,

$$
S(t)=\exp \left(-\int_{0}^{t} \lambda(s) d s\right)
$$

Hence, for this setting it is useful to think of $\lambda(t)$ as the hazard on the seat survival (i.e., arrivals create sales). As a result of an arrival and sales, a seat does not survive. Next, we need to model the time-inhomogenous $\lambda(t)$ to explore the relation between observed covariates and the purchase timing of tickets using Equation (1).

In Figures 1(a) and 1(b), we graph the total sales of both subscribers and occasional buyers, respectively, in every week for every concert in the first season. In Figure 1(a), we see that the sales pattern for subscribers starts with a peak, and then (roughly) decreases, with smaller peaks progressively. In contrast, in Figure 1(b), we see spikes in the sales pattern for occasional buyers towards the end of the horizon.

Typically, the exponential distribution characterized by the scale parameter $\lambda$ is used to model stationary arrivals. However, it is not flexible enough to cover the non-stationary arrivals seen in our data, as seen in Figures 1(a) and 1(b). Such observations indicate that a baseline hazard rate should have the capability to change with time.

We use the Weibull distribution for the link between the arrivals of customers and the timing of ticket sales. The probability density function of a Weibull random variable $t$ is 


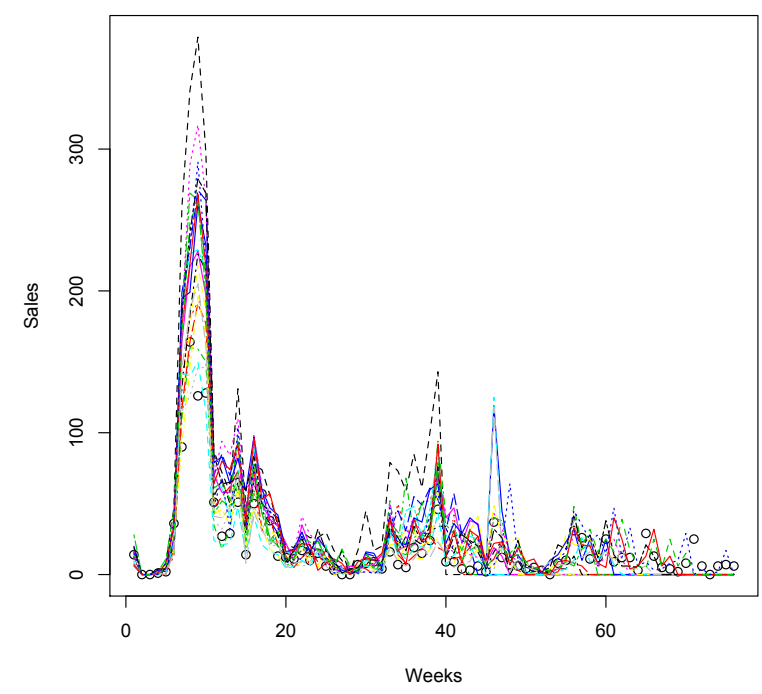

(a)

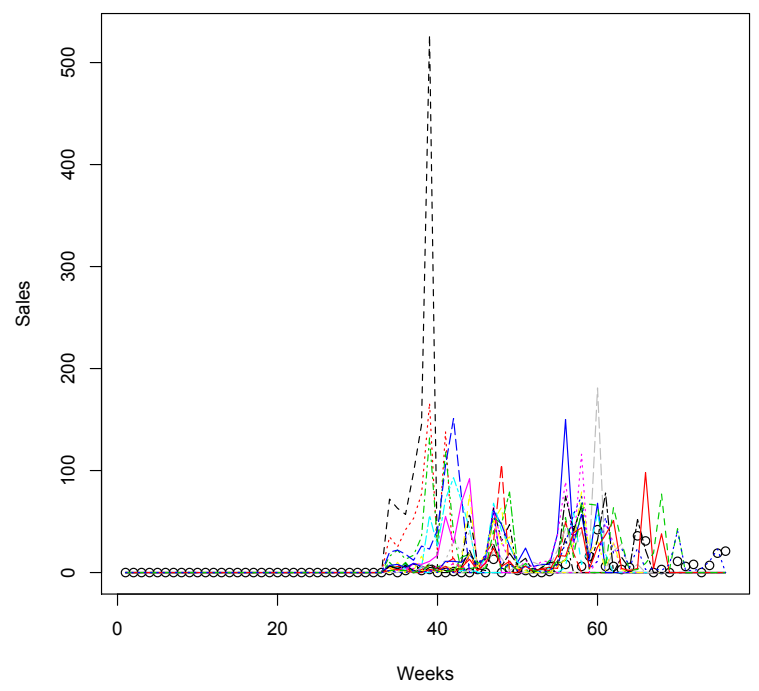

(b)

Figure 1: Number of tickets sold to subscribers per week for every concert on the left. Number of tickets sold to occasional buyers per week for every concert on the right.

$f(t ; \lambda, k)=\lambda k(\lambda t)^{k-1} e^{-(\lambda t)^{k-1}}$ for $t \geq 0$, and 0 otherwise. The parameters $\lambda$ and $k$ account for the scale and shape of the probability density function, respectively. The Weibull distribution gives a distribution for which the hazard rate is proportional to the power of time, i.e., $\lambda_{0}(t ; \lambda, k)=\lambda k(\lambda t)^{k-1}$.

We are interested in the impact of the organization's pricing decisions on the likelihood of selling a ticket over time when controlling for some concert- and venue-related factors. We use an exponential specification for the link between the hazard rate and the organization, concert- and venue-related factors. Let $x(t)$ be the vector of factors that may have an influence on the likelihood of selling a ticket to a consumer at time $t$. We propose:

$$
\Lambda\left(t ; \lambda, k, \beta, x_{t}\right)=\lambda_{0}(t ; \lambda, k) e^{x^{\prime}(t) \beta}=\lambda k(\lambda t)^{k-1} e^{x^{\prime}(t) \beta},
$$

where $\lambda_{0}(t ; \lambda, k)$ is the baseline hazard rate at time $t$, and $\beta$ is the vector of parameters that shows the impact of changes in factors on hazards of selling a ticket at every point in time. 
This exponential link is also known as the proportional hazards framework in the survival analysis literature (Cox 1972). We use the exponential specification to account for potential non-linear effects of the changes in factors on the hazard rate. See Kiefer (1988) for examples of the use of parametric baseline hazard models in econometrics with similar motives, as in our research.

\subsection{Factors Influencing Hazard Rates}

There are a variety of customer categories in the data. Subscribers commit to purchasing different pre-set quantities of tickets: subscribers who subscribe to all 21 performances, 14-show subscribers, and 7-show subscribers. It is only a commitment to attend a specific number of shows; subscribers are free to select the specific choice of shows to attend throughout the season (and may infrequently incur additional charges for the changes). Hence, the actual timing of the ticket purchases for a particular show is the date when the subscriber informs the theater of this final decision, which we tabulate. In our analysis, the subscribers, regardless of the number of shows that they committed to attend, are all grouped together and labeled as "subscribers." The "occasional buyers" may buy tickets to multiple shows, but purchase their tickets to each show separately. In our data set, occasional buyers typically buy tickets for about two shows.

Figures 1(a) and 1(b) show that there is a notable difference between the timing of purchases by subscribers and occasional buyers. To account for this difference, we use different proportional hazard rate specifications for the two customer categories using Equation (2),

$$
\begin{aligned}
& \Lambda_{s}\left(t ; \lambda_{s}, k_{s}, \beta_{s}, x_{s}(t)\right)=\lambda_{s} k_{s}\left(\lambda_{s} t\right)^{k_{s}-1} e^{x_{s}^{\prime}(t) \beta_{s}} \\
& \Lambda_{o}\left(t ; \lambda_{o}, k_{o}, \beta_{o}, x_{o}(t)\right)=\lambda_{o} k_{o}\left(\lambda_{o} t\right)^{k_{o}-1} e^{x_{o}^{\prime}(t) \beta_{o}}
\end{aligned}
$$

where $x_{s}(t)$ and $x_{o}(t)$ contain factors such as the average discount received by subscribers and occasional buyers at time $t\left(\operatorname{AvgDisc}_{s}(t)\right.$ and $\left.\operatorname{AvgDisc}_{o}(t)\right)$, a dummy variable repre- 
senting if time $t$ is the last week before the show ( LastWeek $(t))$, three dummy variables to account for unobserved performance day-related effects (Thurs, Sat, and Sun) since the same concert can be performed on Thursday, Friday, Saturday, or Sunday in that week, 20 dummy variables to account for unobserved concert-related effects from 21 different concerts in a season (Concert $2, \ldots$, Concert 21$)$, and a dummy variable to account for seasonal change in sales from the 2008-09 season to the 2009-2010 season (Year2). We also include an additional dummy variable $(P h o n e(t))$ in $x_{s}(t)$ to account for the telephone marketing campaign of the subscription packages (starting around the sixth week and ending around the eleventh week of the season, see Figure 1(a)). This variable becomes 1 if time $t$ is between the sixth and eleventh weeks; otherwise the value is 0 . Hence, the hazard rate of sales to these two customer categories may change over time due to time-related effects, and it may also change based on the organization's pricing decisions, or performance day and concert-related effects.

The management provides different types of discounts to the patrons for several historic reasons but they never provide a higher discount than the previous one throughout the season for any concert. We see that the discounts used by customers always decrease over time until the performance week. The opposite of this strategy may have caused the customers to delay their purchases to buy the tickets at a higher discount later in the season, as depicted by Li et al. (2014) in the airline industry. The organization's current pricing strategy prevents

such purchase behavior in this setting. We explore the impact of these discounts received by subscribers and occasional buyers on timing of their purchases with $A v g D i s c_{s}(t)$ and $\operatorname{AvgDisc} c_{o}(t)$.

\subsection{Competing Hazards Framework}

To model the ticket sales, we consider the competing risks framework (Kalbfleisch and Prentice 2002), under which the two streams of customers compete for the same seat. Also see, Han and Hausman (1990) use the framework to study the unemployment rate and its different causes, and Braun and Schweidel (2011) who study customer churn. Similarly, we 
perceive the tickets as our test subjects and model their cause-specific sales. Recall that subscribers and occasional buyers are from two different pools with non-stationary rates. Each ticket is available to both categories. In this case, if one pool sends a customer earlier than the other, the seat is given to the earliest arrival. We employ this framework for every seat in the theater.

We index all shows by $i$ where $i \in\{1, \ldots, N\}$. Let $T_{i}$ stand for the ordinal value of the performance week of show $i$. Thus, for each show, we start the horizon at $T_{i}$ weeks prior to the performance week. $T_{i}$ increases in the order of the show indexes $i$. Thus, the season concludes during week $T_{N}$. Recall that multiple performances of the same show happen during the same week on different days. These same performances are indexed chronologically based on the performance day and they have the same performance week value. We group together the zones as follows: the expensive zones (1 and 2), mid-price zones $(3,4,5)$, and cheap zones $(6,7,8)$. They are aggregated together according to similar aspects of price and the quality of the seats. Separate estimation of the zones in expensive, mid-price and cheap tiers provides very similar estimates. We index all three tiers by $j$ where $j \in\{1,2,3\}$ stands for the expensive, mid-price, and cheap zones, respectively.

We next define the likelihood of the ticket (seat) sale from tier $j$ for show $i$ at time $t$ to a particular customer type. If the ticket is sold in week $t$, then the ticket should not be purchased by any types until week $t$. The ticket would survive the purchase by customer type $l \in\{s, o\}$ with probability:

$$
\begin{aligned}
S_{l j}\left(t ; \lambda_{l j}, k_{l j}, \beta_{l j}, x_{l j}(t)\right) & =\exp \left(-\int_{0}^{v} \Lambda_{l j}\left(v ; \lambda_{l j}, k_{l j}, \beta_{l j}, x_{l j}(t)\right) d v\right) \\
& =\exp \left(-\lambda_{l j}^{k_{l j}} \sum_{v=0}^{t-1} \exp \left(x_{l j}^{\prime}(v) \beta_{l j}\right) \int_{v}^{v+1} k_{l j} v^{k_{l j}-1} d v\right) \\
& =\exp \left(-\lambda_{l j}^{k_{l j}} \sum_{v=0}^{t-1} \exp \left(x_{l j}^{\prime}(v) \beta_{l j}\right)\left((v+1)^{k_{l j}}-v^{k_{l j}}\right)\right) .
\end{aligned}
$$

The probability of a ticket surviving until week $t$ is $\prod_{l \in\{s, o\}} S_{l j}\left(t ; \lambda_{l j}, k_{l j}, \beta_{l j}, x_{l j}(t)\right)$. Hence, 
the probability for a ticket, that is observed to be sold in week $t$, to be purchased by customer type $l$ would be $\Lambda_{l j}\left(t ; \lambda_{l j}, k_{l j}, \beta_{l j}, x_{l j}(t)\right) \prod_{l \in\{s, o\}} S_{l j}\left(t ; \lambda_{l j}, k_{l j}, \beta_{l j}, x_{l j}(t)\right)$. Let $d_{s j}$ indicates whether the ticket is sold to a customer from the subscriber category at time $t$, and $d_{o j}$ indicates whether the ticket is sold to a customer from the occasional buyer category at time $t$. Clearly, $d_{s j}+d_{o j}=1$ because the ticket can be sold to only one customer category. We can then write the likelihood contribution for each ticket sold at time $t$ for tier $j$ as:

$$
\prod_{l \in\{s, o\}} \Lambda_{l j}\left(t ; \lambda_{l j}, k_{l j}, \beta_{l j}, x_{l j}(t)\right)^{d_{l j}} S_{l j}\left(t ; \lambda_{l j}, k_{l j}, \beta_{l j}, x_{l j}(t)\right)
$$

A ticket for show $i$, which was not purchased until the performance week, would mean that it survived all purchases over $T_{i}$ weeks. Then, this ticket's likelihood contribution would be $\prod_{l \in\{s, o\}} S_{l j}\left(T_{i} ; \lambda_{l j}, k_{l j}, \beta_{l j}, x_{l j}\left(T_{i}\right)\right)$.

\subsection{Estimation Scheme}

We find the maximum likelihood estimators for $\lambda_{s j}, k_{s j}, \lambda_{o j}, k_{o j}, \beta_{s j}$, and $\beta_{o j}$ for all tiers $j=1,2,3$ through the product of likelihood contributions from each ticket (described in subsection 3.3). Let $M_{j}$ be the total number of available seats in tier $j$, and $m=1, \ldots, M_{j}$ be the index of a seat in tier $j$. We can write the total likelihood function for tier $j$ as:

$$
L_{j}=\prod_{i=1}^{N} \prod_{m=1}^{M_{j}} \prod_{l \in\{s, o\}} \Lambda_{l j}\left(t_{i m} ; \lambda_{l j}, k_{l j}, \beta_{l j}, x_{l j}\left(t_{i m}\right)\right)^{d_{i m l j}} S_{l j}\left(t_{i m} ; \lambda_{l j}, k_{l j}, \beta_{l j}, x_{l j}\left(t_{i m}\right)\right) .
$$

Note that the overall likelihood function for tier $j$ is a product of likelihoods for each type of customer category $l$. This implies that we can estimate the parameters for each customer category by maximizing the separate likelihoods of each customer category and can save time with lower number of parameters to estimate in each run. We run the estimations separately for each customer category. 


\section{Data}

This research is based on data collected during two seasons of ticket sales transactions at the individual level for a renown symphony orchestra in the Northeast region of the United States. The data was collected from several departments and at the ticket booth, and tabulated.

The data include 53 performances during the 2008-09 season (Year 1) and 54 performances during the 2009-10 season (Year 2). Each season has about 21 weeks of concerts. In each of the 21 weeks, a different musician presents a distinct repertoire, with most of the repertoires conducted by the orchestra conductor.

The theater has a maximum seating capacity of $2500+$ seats. Our data covers 9,833 distinct customers - a few special customers, many regulars, and various categories of subscribers. From our data, we note that the concerts are rarely sold out. For example, in Year 1, the average sales was 1,661 per concert (with a standard deviation of 457) which is less than $65 \%$ of the capacity of the venue. During Year 1, only eight shows had sales in excess of $80 \%$ of the venue capacity.

The prices of these seats are determined by the seat quality associated with the zone - in other words, the acoustic experience and the visual line of sight to the stage. There is a significant price difference between the zones and days. For instance, on Thursdays (Fridays/Saturdays), the high-priced zones are sold at an advertised ticket price of $\$ 41.50$ $(\$ 78.50)$ and the lowest priced zone ticket is about $\$ 12.50(\$ 19.50)$.

Typically, ticket sales begin several weeks in advance of the first concert of the season. In our data, the ticket sales begin as early as 39 weeks prior to the first concert week. Thus, our data covers sales over 76 weeks for the full season for both years.

It is hard to obtain individual income level data, for this customer population. Nevertheless, we use ZIP Code location data for customers, whenever available. The customers are dispersed over three ZIP Codes, which did not differ much in income levels to affect our main findings. 


\subsection{Preliminary Processing for Calibration and Validation}

There are a variety of discount options and programs available to customers. The mean price of the ticket sold is $\$ 28.63$, and the standard deviation is $\$ 16.08$. The average Gini coefficient for the price of the ticket is 0.216 (and the standard deviation is 0.031 ), which indicates that the expected absolute difference between the prices of any two tickets chosen at random is about $42 \%$ of the mean price.

We use the data from individual purchase transactions from all 53 performances of the 21 concerts in the first season (Year 1) and all 35 performances of the first 14 concerts in the second season (Year 2) to estimate our model. In Section 5.1, we validate our model on the performances of the remaining seven concerts of Year 2. From the total of 54,945 transactions observed in this data, 7,313 transactions of complementary or large group ticket

sales were deleted. We code each performance, labeling them with the values $\{1,2,3, \ldots$, $88\}$, in chronological order.

In each purchase transaction, we observe which one of the 21 concerts is selected, which performance day of that concert is selected, and when the transaction took place. We use this information to identify the week the performance takes place, as well as the week the tickets were purchased during Year 1 and Year 2. The information for the transaction week is used to set the indicator variables such as LastWeek(t), Phone(t), Thurs, Sat, and Sun. The information on the transaction year and the concert is used to set the dummy variable Year 2, and the concert-related dummy variables (Concert2, ..., Concert21).

Each purchase transaction in the data reflects not only the number of tickets sold and their transaction price, as well as the type of customer purchasing the ticket. We extract from this data the discount used by that customer category. We aggregate all discounts to calculate the average discount used by each customer category, $\operatorname{AvgDisc}_{s}(t)$ and $A v g D i s c_{o}(t)$, in each week $t$ throughout Year 1 and Year 2. 


\section{Results}

We have established the formation of competing hazards that are based on time, the organization's pricing decisions, performance day, and concert-related parameters. Table 1 presents the coefficient estimates from the estimations for each tier.

Subscribers and occasional buyers differ in their arrival patterns. The parameter estimates for the scale $(\lambda)$ and the shape $(k)$ are significant (at 1\% level) for all customer categories and tiers. Comparing $\lambda$ and $k$ between subscribers and occasional buyers for each tier shows that there is a significant change in the value of the estimates based on asymptotic $t$-tests of the difference in magnitude at the $\alpha=0.01$ level. We see that $\lambda$ for subscribers is higher than $\lambda$ for occasional buyers, and $k$ for subscribers is lower than $k$ for occasional buyers for all tiers. Thus, the majority of subscribers purchase their tickets earlier than the majority of occasional buyers, who purchase their tickets later in the selling horizon.

Table 1 shows that the impact of the average discount (AvgDisc) on hazard rate of subscribers is positive and statistically significant (at the 1\% level) for each tier. The hazard rate in a week would be adjusted up by the exponential of the estimate for each $1 \%$ discount to the customer. For instance, if the organization provides an additional $1 \%$ discount to subscribers for a ticket purchase from an expensive tier, then the hazard rate for subscribers would be adjusted up by $\exp (0.01 \times 1.6)=1.016$. Hence, for a given week, the average sales rate to subscribers would increase by $1.6 \%$.

Similarly, for each tier, we find that the impact of the average discount on the hazard rate of occasional buyers is positive and statistically significant (at the $1 \%$ level except for the mid-priced tier). For instance, if the organization provides an additional $1 \%$ discount to occasional buyers for a purchase of a ticket from an expensive tier, then the hazard rate for occasional buyers would be adjusted up by $\exp (0.01 \times 0.487)=1.005$. Hence, for a given week, the average sales rate to occasional buyers would increase by $0.5 \%$.

Comparing the increases in hazard rate for an additional discount shows that subscribers value the discounts more than occasional buyers for all tiers. This was expected since oc- 


\begin{tabular}{lllllll}
\multirow{2}{*}{ Coefficients } & \multicolumn{2}{c}{ Expensive } & \multicolumn{2}{c}{ Mid-priced } & \multicolumn{2}{c}{ Cheap } \\
& Subscriber & Occasional & Subscriber & Occasional & Subscriber & Occasional \\
\hline \multirow{2}{*}{ N } & $0.020^{* * *}$ & $0.013^{* * *}$ & $0.017^{* * *}$ & $0.013^{* * *}$ & $0.016^{* * *}$ & $0.013^{* * *}$ \\
& $(0.001)$ & $(0.001)$ & $(0.001)$ & $(0.001)$ & $(0.001)$ & $(0.001)$ \\
\multirow{4}{*}{ AvgDisc } & $1.404^{* * *}$ & $7.024^{* * *}$ & $1.598^{* * *}$ & $7.331^{* * *}$ & $2.001^{* * *}$ & $8.083^{* * *}$ \\
& $(0.010)$ & $(0.132)$ & $(0.008)$ & $(0.044)$ & $(0.013)$ & $(0.094)$ \\
Thurs & $1.600^{* * *}$ & $0.487^{* * *}$ & $0.865^{* * *}$ & $0.057^{*}$ & $0.970^{* * *}$ & $0.398^{* * *}$ \\
& $(0.095)$ & $(0.056)$ & $(0.038)$ & $(0.034)$ & $(0.033)$ & $(0.045)$ \\
Sat & $-0.204^{* * *}$ & $0.214^{* *}$ & $0.087^{* * *}$ & -0.024 & 0.013 & 0.047 \\
& $(0.037)$ & $(0.075)$ & $(0.026)$ & $(0.060)$ & $(0.032)$ & $(0.072)$ \\
Sun & $-0.059^{* * *}$ & $0.082^{* *}$ & $-0.123^{* * *}$ & $0.103^{* * *}$ & $-0.185^{* * *}$ & $0.132^{* * *}$ \\
& $(0.017)$ & $(0.035)$ & $(0.012)$ & $(0.021)$ & $(0.015)$ & $(0.024)$ \\
Year 2 & $0.106^{* * *}$ & $-0.127^{* * *}$ & $0.340^{* * *}$ & $-0.123^{* * *}$ & $0.302^{* * *}$ & $0.115^{* * *}$ \\
& $(0.016)$ & $(0.037)$ & $(0.011)$ & $(0.023)$ & $(0.013)$ & $(0.025)$ \\
LastWeek & $-0.040^{* * *}$ & $0.156^{* * *}$ & $-0.081^{* * *}$ & -0.031 & $-0.148^{* * *}$ & 0.034 \\
\multirow{2}{*}{ Phone } & $(0.015)$ & $(0.035)$ & $(0.011)$ & $(0.023)$ & $(0.013)$ & $(0.025)$ \\
& $1.872^{* * *}$ & $2.673^{* * *}$ & $1.557^{* * *}$ & $2.843^{* * *}$ & $1.393^{* * *}$ & $2.708^{* * *}$ \\
\hline Log Likelihood & $(0.039)$ & $(0.039)$ & $(0.028)$ & $(0.023)$ & $(0.031)$ & $(0.025)$ \\
\hline
\end{tabular}

Note. The models for subscribers and occasional buyers for all price tiers also include concert related indicators. Standard errors are shown in parentheses. ${ }^{*}, * *$, and $* * *$ denote significance at the $10 \%, 5 \%$, and $1 \%$ confidence level, respectively.

Table 1: Estimation results for expensive, mid-priced, and cheap tiers.

casional buyers attend concerts occasionally, and they might not be aware of the value of the discounts; subscribers likely pay close attention to prices to reduce their total payment for attending multiple concerts. We also find that the hazard rates for both customer categories increase most with an additional discount in the expensive tier, which indicates a high interest by price sensitive customers.

We find that another organization-related factor, the telephone marketing campaign (Phone) for sales to subscribers, also has a positive and statistically significant effect (at the $1 \%$ level) on the hazard rates of subscribers for each tier. For instance, the hazard rate of subscribers for the expensive tier for a given week is $400 \%$ higher, as evident by the huge spike of sales between the sixth and eleventh weeks in subscriptions for every concert (Figure $1(\mathrm{a}))$. 
Not surprisingly, the hazard rates for both subscribers and occasional buyers go up during the last week before a performance; this increase is higher for occasional buyers. It is normal for any customer category to make last-minute purchase decisions. For instance, Table 1 shows that the hazard rate on the LastWeek before a performance increases by $|\exp (1.872)-1| \times 100=550 \%$ for subscribers and by $|\exp (2.673)-1| \times 100=1,348 \%$ for occasional buyers relative to other weeks. Figures 1(a) and 1(b) also confirm this last minute increases in sales, with spikes later in the season right before the performance weeks.

Finally, the hazard rates for a Saturday performance are generally lower for subscribers and higher for occasional buyers relative the Friday performance of the same material for all tiers. For instance, the hazard rate decreases by $|\exp (-0.059)-1| \times 100=5.73 \%$ for subscribers and increases by $|\exp (0.082)-1| \times 100=8.55 \%$ in the expensive tier. This is consistent with the observation that Fridays are the busiest concert evenings, with subscribers occupying most of the seats.

To summarize, subscribers and occasional buyers exhibit significant differences in their purchase patterns throughout the selling period. Their purchase timings also differ in response to the organization's pricing strategies, the performance day related factors, and to some other factors. This shows that some pricing strategies can be used to change the timing of ticket sales to a particular customer category throughout the season.

\section{$5.1 \quad$ Out-of-Sample Tests}

In this section, we perform out-of-sample tests for each tier to illustrate the accuracy of the estimation. To this end, we use all the shows for the last seven concerts for prediction and testing of the model. The testing is done for each customer category and tier in isolation.

Let $P_{s j}(t)$ denote the ex ante probability of a seat from tier $j$ being sold to a subscriber in week $t$. Similarly, let $P_{o j}(t)$ denote the ex ante probability of a seat from tier $j$ being sold 
to an occasional buyer in week $t$. These probabilities are given by:

$$
\begin{aligned}
& P_{s j}(t)=\Lambda_{s j}\left(t ; \lambda_{s j}, k_{s j}, \beta_{s j}, x_{s j}(t)\right) \prod_{l \in\{s, o\}} S_{l j}\left(t ; \lambda_{l j}, k_{l j}, \beta_{l j}, x_{l j}(t)\right) \\
& P_{o j}(t)=\Lambda_{o j}\left(t ; \lambda_{o j}, k_{o j}, \beta_{o j}, x_{o j}(t)\right) \prod_{l \in\{s, o\}} S_{l j}\left(t ; \lambda_{l j}, k_{l j}, \beta_{l j}, x_{l j}(t)\right)
\end{aligned}
$$

The seat's selling propensity to each customer category in each period is independent of each other. Therefore, the predicted number of sales to subscribers and occasional buyers in week $t$ has a multinomial distribution. Let $m_{s j}(t)$ and $\sigma_{s j}(t)$ denote the mean and standard deviation for the subscriber category of this distribution, respectively. Similarly, let $m_{o j}(t)$ and $\sigma_{o j}(t)$ denote the mean and standard deviation for the occasional buyer category of this distribution, respectively. Then, given that tier $j$ has $M_{j}$ seats, $m_{l j}(t)=M_{j} P_{l j}(t)$ and $\sigma_{l j}(t)=\sqrt{M_{j} P_{l j}(t)\left(1-P_{l j}(t)\right)}$ for customer categories $l \in\{o, s\}$. Furthermore, the predicted number of aggregate ticket sales from tier $j$ to customer category $l$ for show $i$ is $\sum_{t=1}^{T_{i}} m_{l j}(t)=M_{j} \sum_{t=1}^{T_{i}} P_{l j}(t)$. Let $a_{l} j(t)$ denote the actual number of tickets sold from tier $j$ to customer category $l \in\{o, s\}$ in week $t$.

We consider the absolute errors in predicting the aggregate sales rates to customer categories $l \in\{o, s\}$ as the performance metric for the out-of-sample test. This measure is given by:

$$
\text { Absolute Error }_{i l j}=\frac{1}{M_{j}}\left|\sum_{t=1}^{T_{i}} m_{l j}(t)-\sum_{t=1}^{T_{i}} a_{l j}(t)\right| \text {. }
$$

Table 2 presents the averages of the performance metric across all shows in the prediction sample for different customer categories and tiers. The results show that our model is fairly accurate in predicting the aggregate ticket sales for both subscribers and occasional buyers.

Figure 2 provides a detailed comparison of the predicted and actual sales to subscribers and occasional buyers for only the Friday show of the $19^{\text {th }}$ concert in the second season. In addition to $m_{l j}(t)$ and $\sigma_{l j}(t)$, the graphs also show $m_{l j}(t) \pm 2 \sigma_{l j}(t)$ over time for customer categories $l \in\{o, s\}$ and for all tiers. These graphs help us to assess the accuracy of the 


\begin{tabular}{lcc}
\multirow{2}{*}{ Seating Tier } & \multicolumn{2}{c}{ Absolute Error } \\
& Subscriber & Occasional Buyer \\
\hline Expensive & 0.19 & 0.04 \\
Mid-price & 0.29 & 0.06 \\
Cheap & 0.27 & 0.07 \\
\hline
\end{tabular}

Table 2: Averages of the Performance Metrics Across All Shows

prediction in relation to the inherent variability of the sales to subscribers and occasional buyers.

\section{$5.2 \quad$ Pricing Experiments}

In this section, we discuss the ticket revenue management process using the estimated hazard rate parameters. We perform what-if analyses to assess the impact of changes in the pricing policy.

We construct the simulation along the lines of the usual discrete-event simulations for a tier of a show. In the simulation, the remaining seats for every week are either sold to subscribers or occasional buyers, with probabilities depicted in Equations (6) and (7), respectively, or they survive to the next week. We repeat this procedure until the tier runs out of seats or we reach the performance week. Then, we run the simulation on the expensive tier of the Friday shows of seven consecutive concerts in our prediction sample.

We first reconstruct the existing as is performance of the organization's pricing policy. The expensive tier contains $400+$ seats. We start the simulation with these seats by implementing the organization's current discounting policy. For every week, we track which seats are sold to subscribers and occasional buyers, and calculate the corresponding revenues from these sales with the organization's current average discounting policy. Note that separate simulations are run for every one of seven shows. Once all seven simulations end (either by reaching the end of the performance week of a show or if all seats in the tier are sold), we calculate the total revenue. We run these simulations 1,000 times and calculate the average revenue obtained for all seven shows. Table 3 provides the average revenues from the "as-is" 
Subscription ticket sales for the expensive tier

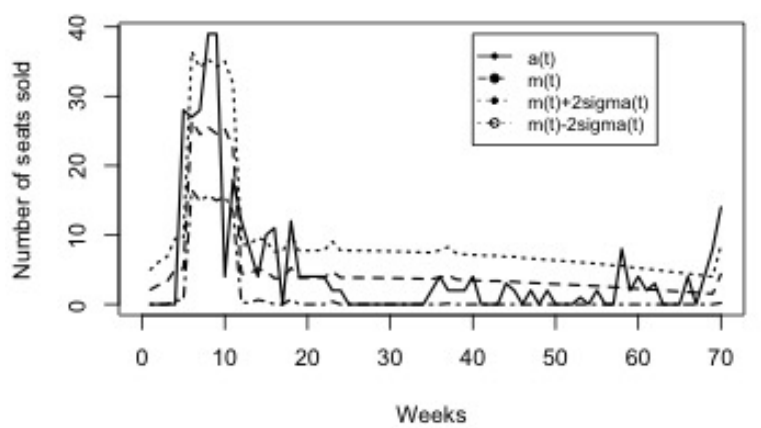

Subscription ticket sales for the mid-priced tier

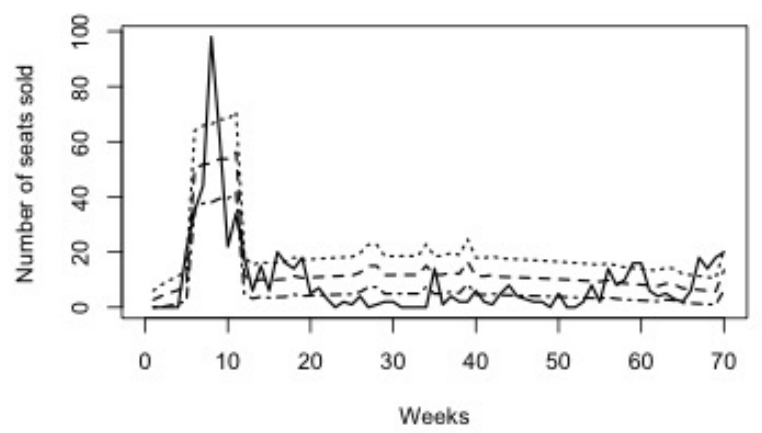

Subscription ticket sales for the cheap tier

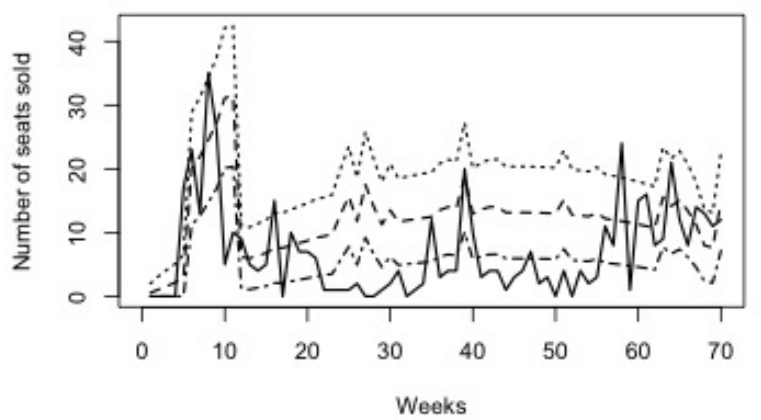

Occasional ticket sales for the expensive tier

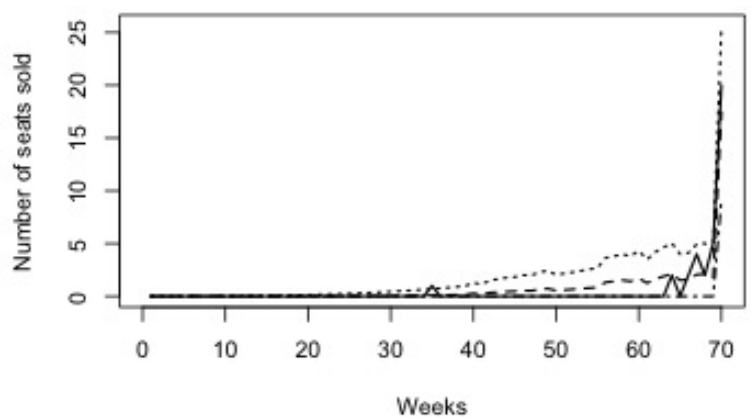

Occasional ticket sales for the mid-priced tier

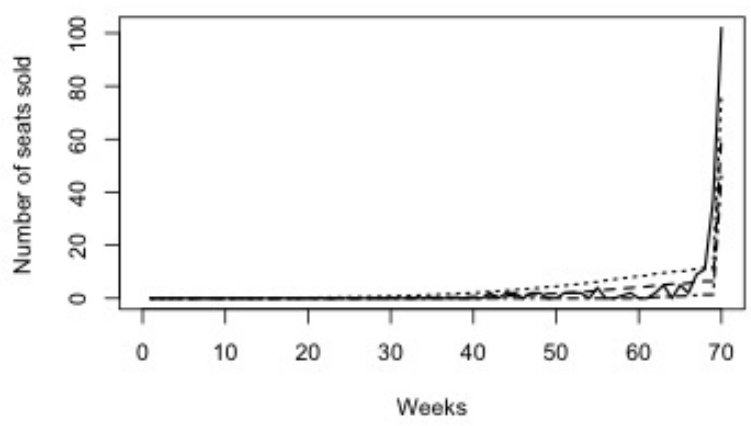

Occasional ticket sales for the cheap tier

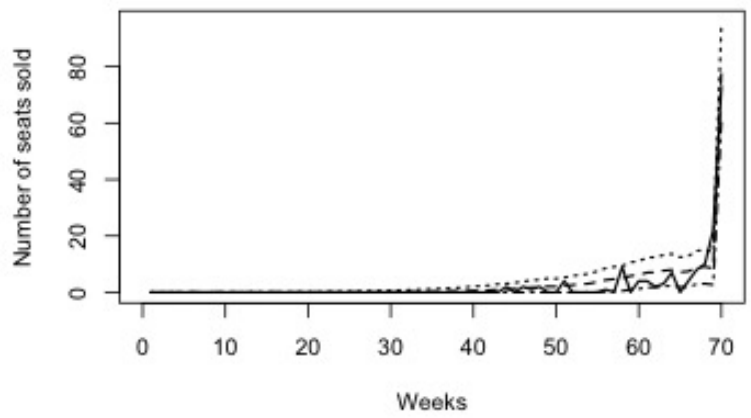

Figure 2: The predicted sales $m(t)$, actual sales $a(t)$, and $m(t) \pm 2 \sigma(t)$ over time for subscribers and occasional buyers and for all seating tiers.

policy for every show. Recall that the orchestra's current operational practice attempts to lift the ticket sales by providing ad-hoc discounts, even earlier in the season.

Next, we consider assessing the impact of changes to the pricing policies. To this end, we evaluate a decreasing monotone discounting (DMD) policy. Under this pricing policy, the 
organization sticks to its current pricing policy for subscribers. For the occasional buyers, the organization starts with some discount and gradually decreases the discount until the performance week. In particular, we test the following policy: 50\% discount in the first 30 weeks of the season, followed by a $30 \%$ discount in the next 20 weeks, then a $10 \%$ discount until two weeks prior to the performance day, and no discount in the last two weeks. The average revenues from this policy is given under the DMD policy column of Table 3 .

\begin{tabular}{cccc} 
Show & Current policy $(\$)$ & DMD Policy $(\$)$ & Revenue Improvement \\
\hline 1 & $16,193.75$ & $16,529.83$ & $2.08 \%$ \\
2 & $16,145.07$ & $16,557.44$ & $2.55 \%$ \\
3 & $16,160.44$ & $16,615.15$ & $2.81 \%$ \\
4 & $15,959.56$ & $16,559.51$ & $3.76 \%$ \\
5 & $15,870.74$ & $16,471.87$ & $3.79 \%$ \\
6 & $15,990.69$ & $16,484.78$ & $3.09 \%$ \\
7 & $15,714.87$ & $16,771.37$ & $6.72 \%$ \\
\hline
\end{tabular}

Table 3: Average revenues under As-Is and Decreasing Monotone Discounting (DMD) pricing policies.

In the Revenue Improvement column in Table 3, we summarize the percentage increase in revenues under the DMD pricing policy relative to the revenues under the as-is pricing policy of the organization. The results show that the commitment to a DMD policy can increase the average revenue per concert by $6.72 \%$ relative to the current pricing policy of the organization.

\section{Conclusions}

In this paper, we empirically explore the role of a non-profit performing arts organization's pricing policy. Nonprofit organizations such as theaters have an objective to sell as many seats as possible, while maintaining or improving customer loyalty, and accruing revenues to meet fixed operational costs. In our paper, two main customer categories are evaluated for their purchasing decisions over two seasons. We use counterfactual pricing experiments to explore discounting policy recommendations and to show how commitment to a decreasing 
monotone discounting policy may play a significant role in the revenue generation capability of an organization.

Our empirical model has the flexibility to account for different degrees of consumer patience for each customer category by measuring the link between the past observed prices and other time-related factors and the current purchase probability through cumulative proportional hazards in survival probabilities of seats. Our model also has the flexibility to account for differing valuations through separate price sensitivity measures in hazard rates for each customer category. Finally, the separate proportional hazard rates give our model the flexibility to account for potential differences between arrival times of subscribers and occasional buyers.

We find that subscribers and occasional buyers have different purchase patterns throughout the season. Results from the competing risks framework show that the likelihood of a ticket sale to a subscriber relative to an occasional buyer is higher earlier during the season, whereas the likelihood of a ticket sale to an occasional buyer is higher relative to a subscriber closer to the performance week. These patterns are independent of the organization's pricing policies for both customer categories.

We also find that discounts play a significant role in attracting more subscribers and occasional buyers during any given performance week. Specifically, the likelihood of a purchase by a subscriber or occasional buyer increases when that customer category can take advantage of a ticket discount. In the light of discount-driven lifts in ticket purchases, we show that an organization can improve its revenue by committing to a non-decreasing pricing policy even if the customer categories exhibit different valuations and arrival times for each performance throughout the season.

Our study of customer purchase tendencies throughout the season provides evidence that discounting decisions may require joint consideration of multiple customer categories. It might be possible that the purchase tendency of one customer category might also change based on the discounts offered to other customer categories in the market. To maintain the 
research focus, our model assumes an independent hazard rate of a customer category from the discount received by other customer category. We employ a parametric model. Nonparametric characterization of hazards in competing risks frameworks remains a challenging future research direction.

Our competing hazards framework can be directly applied to other non-profit settings with charity events or blood donation events to explore the change in donation tendencies due to incentives offered by the organization. By integrating appropriate covariates that are specific to those settings, we believe that the primary competing hazard model structure can be translated to most settings with minimal variations.

\section{Acknowledgments}

We thank the performing arts organization for the discussions of their operations, ticket selling process and access to the data.

\section{References}

Besbes, O., I. Lobel. 2015. Intertemporal price discrimination: Structure and computation of optimal policies. Management Science 61(1) 92-110.

Bitran, G., S. V. Mondschein. 1997. Periodic pricing of seasonal products in retailing. Management Science 43(1) 64-79.

Braun, M., Z. A. Schweidel. 2011. Modeling customer lifetimes with multiple causes of churn. Marketing Science 30(5) 881-902.

Caldentey, R., Y. Liu, I. Lobel. 2014. Intertemporal pricing without priors. Working Paper, New York University, New York, NY. 
Cox, D. R. 1972. Regression models and life-tables. Journal of the Royal Statistical Society. Series B (Methodological) 34(2) 187-220.

Dana, J. D. 1998. Advance-purchase discounts and price discrimination in competitive markets. Journal of Political Economy 106(2) 395-422.

Deprez, E. É. 2015. Ski resorts experiment with dynamic pricing. Bloomberg Business (February 25). http://www.bloomberg.com/news/articles/2015-02-25/ski-lift-costbecomes-moving-target-as-dynamic-prices-hit-slopes.

Deshpande, V., M. Arikan. 2012. The impact of airline flight schedules on flight delays. Manufacturing and Service Operations Management 14(3) 423-440.

Fader, P. S., B. G. S. Hardie. 2007. How to project customer retention. Journal of Interactive Marketing 21(1) 76-90.

Feng, Y., G. Gallego. 1995. Optimal starting times for end-of-season sales and optimal stopping times for promotional fares. Management Science 41(8) 1371-1391.

Feng, Y., G. Gallego. 2000. Perishable asset revenue management with Markovian time dependent demand intensities. Management Science 46(7) 941-956.

Gallego, G., G. van Ryzin. 1994. Optimal dynamic pricing of inventories with stochastic demand over finite horizons. Management Science 40(8) 999-1020.

Gallego, G., G. van Ryzin. 1997. A multiproduct dynamic pricing problem and its applications to network yield management. Operations Research 45(1) 24-41.

Han, A., J. A. Hausman. 1990. Flexible parametric estimation of duration and competing risk models. Journal of Applied Econometrics 5(1) 1-28.

Heskett, J. L., W. E. Sasser Jr. 2010. Southwest Airlines: In a different world. Harvard Business School Case 910-419 April. (Revised January 2013). 
Jerath, K., S. Netessine, S. K. Veeraraghavan. 2010. Revenue management with strategic customers: Last-minute selling and opaque selling. Management Science 56(3) 430-448.

Kalbfleisch, J. D., R. L. Prentice. 2002. Competing risks and multistate models. The statistical analysis of failure time data, 2nd ed. John Wiley \& Sons, Inc., Hoboken, NJ.

Kiefer, N. M. 1988. Economic duration data and hazard functions. Journal of Economic Literature 26(2) 646-679.

Kleinbaum, D. G., M. Klein. 2012. Survival analysis: A self-learning text. 3rd ed. SpringerVerlag, New York, NY.

Koenigsberg, O., E. Muller, N. J. Vilcassin. 2008. easyJet pricing strategy: Should low-fare airlines offer last-minute deals? Quantitative Marketing Economics 6(3) 279-297.

Li, J., N. Granados, S. Netessine. 2014. Are consumers strategic? Structural estimation from the air-travel industry. Management Science 60(9) 2114-2137.

Liu, Y., W. L. Cooper. 2014. Optimal dynamic pricing with patient customers. Working Paper, University of Minnesota, Minneapolis, MN.

Moe, W., P. S. Fader. 2002. Using advance purchase orders to forecast new product sales. Marketing Science 21(3) 347-364.

Ovchinnikov, A., J. M. Milner. 2011. Revenue management with end-of-period discounts in the presence of customer learning. Production and Operations Management 21(1) 69-84.

Schweidel, D. A., P. S. Fader, E. T. Bradlow. 2008a. A bivariate timing model of customer acquisition and retention. Marketing Science 27(5) 829-843.

Schweidel, D. A., P. S. Fader, E. T. Bradlow. 2008b. Understanding service retention within and across cohorts using limited information. Journal of Marketing 72(1) 82-94. 
Schweitzer, V. 2011. Survival strategies for orchestras. The New York Times (May 29) AR16.

$\mathrm{Su}, \mathrm{X}$. 2007. Intertemporal pricing with strategic customer behavior. Management Science 53(5) 726-741.

Surowiecki, J. 2014. In praise of efficient price gouging. MIT Technology Review (September/October) $74-77$.

Talluri, K. T., G. J. van Ryzin. 2004. The Theory and Practice of Revenue Management. Kluwer Academic Publishers, Norwell, MA.

Terwiesch, C., Z. J. Ren, T. H. Ho, M. A. Cohen. 2005. An empirical analysis of forecast sharing in the semiconductor equipment supply chain. Management Science 51(2) 208220. 